\title{
Exfoliação capsular verdadeira: relato de dois casos
}

\author{
True capsular exfoliation: report of two cases
}

\author{
Eduardo Ferrari Marback ${ }^{1}$ \\ Barbra de Melo Rolemberg'2 \\ Haylton Gonçalves Silva Filho ${ }^{3}$ \\ Rita deCássia Aquino Araújo ${ }^{4}$ \\ Marcelo Siqueira de Freitas ${ }^{5}$
}

\begin{tabular}{|l|}
\hline RESUMO \\
\hline Relatamos dois casos de exfoliação verdadeira da cápsula, acontecendo \\
em pacientes idosos sem história de exposição prolongada a altas tempe- \\
raturas ou passado de inflamação intra-ocular. Os aspectos biomicros- \\
cópicos, anátomo-patológicos e possíveis implicações cirúrgicas são \\
comentados.
\end{tabular}

Descritores: Cápsula do cristalino/patologia; Cápsula do cristalino/cirurgia; Doenças do cristalino/patologia; Doenças do cristalino/diagnóstico; Doenças do cristalino/cirurgia; Relatos de caos [Tipo de publicação]

\section{INTRODUÇÃO}

A exfoliação verdadeira da cápsula do cristalino é uma doença rara, na qual ocorre uma separação das lamelas superficiais da cápsula anterior, permanecendo com aderência na área central e extremidade livre na câmara anterior ${ }^{(1-3)}$. A doença classicamente acomete indivíduos com história de exposição à radiação infra-vermelha a partir de materiais em alta temperatura ("sopradores" de vidro, ferreiros, padeiros, etc) $)^{(1-3)}$. Embora existam relatos do acometimento de pacientes idosos sem história de exposição prolongada a altas temperaturas, e outros em associação com inflamação intra-ocular ${ }^{(4-5)}$.

Com a popularização do uso da capsulorrexe curvilínea contínua na cirurgia da catarata, surgiu a preocupação sobre a integridade da cápsula nestes olhos ${ }^{(2-3)}$. Começaram também a aparecer relatos da "capsulorrexe em anel duplo", considerada um estágio subclínico da exfoliação verdadeira da cápsula, e sugestões de estratégias cirúrgicas para contornar o problema $^{(6-7)}$.

Relatamos aqui dois casos de exfoliação verdadeira da cápsula, enfatizando os achados anátomo-patológicos e estratégia cirúrgica no caso submetido a facoemulsificação.

\section{RELATO DOS CASOS}

fessor Edgard Santos da Universidade Federal da Bahia

- UFBA - Salvador (BA) - Brasil. Oftalmologista do Instituto de Olhos Freitas - Salvador (BA) - Brasil

${ }^{2}$ Aluna do Curso de Especialização em Oftalmologia da UFBA - Salvador (BA) - Brasil.

3 Aluna do Curso de Especialização em Oftalmologia da UFBA - Salvador (BA) - Brasil.

${ }^{4}$ Oftalmologista do Instituto de Olhos Freitas - Salvador (BA) - Brasil.

${ }^{5}$ Mestre, Diretor Médico do Instituto de Olhos Freitas Salvador (BA) - Brasil.

Endereço para correspondência: Eduardo Marback. Rua Eduardo José dos Santos, 147 - Sala 808 - Salvador (BA) CEP 41940-455

E-mail: marback@ufba.br

Recebido para publicação em 04.03.2008 Aprovação em 27.05.2008

\footnotetext{
Caso 1

Paciente do sexo masculino, mecânico aposentado. Queixa de baixa progressiva da visão à esquerda. Relatava cirurgia de catarata no olho direito (OD) há 10 anos, com resultado ruim. Fazia uso de colírio maleato de timolol há mais de 15 anos. Ao exame, apresenta melhor visão corrigida igual a percepção luminosa no OD e conta dedos a 3 metros no olho esquerdo (OE). A pressão intra-ocular era de $12 \mathrm{mmHg}$ no OD e $10 \mathrm{mmHg}$ no OE. O OD exibia ceratopatia bolhosa, sendo impossível avaliar o restante do segmento anterior. Na biomicroscopia do OE foi evidenciada lamela transparente possuindo extremidade livre na câmara anterior e base aderida à
} 
área circular na parte central da cápsula anterior (Figura 1). O cristalino exibia discreta esclerose nuclear. O nervo óptico apresentava escavação total. Após ser informado do prognóstico reservado para cirurgia de catarata devido ao dano glaucomatoso, e diante da experiência ruim com a primeira cirurgia de catarata, o paciente optou pelo acompanhamento clínico.

\section{Caso 2}

Paciente de 83 anos, dona de casa, com queixa de baixa progressiva da visão. Apresentava melhor acuidade visual corrigida de 20/80 no OD e 20/60 no OE. A pressão intra-ocular e o fundo de ambos os olhos se apresentavam dentro dos padrões da normalidade. A biomicroscopia do OD mostrava lamela semelhante àquela do caso 1 , porém com uma esclerose nuclear de 3+/4+. O OE não apresentava alteração capsular e exibia esclerose nuclear de $2+/ 4+$. Foi submetida a facectomia por facoemulsificação, com implante de lente intra-ocular em ambos os olhos sem intercorrências. Na cirurgia do OD a capsulorrexe foi confeccionada por fora da área de exfoliação. A porção excisada da cápsula anterior foi preservada em formol a 10\%. O estudo anátomo-patológico revelou cápsula anterior espessada, com porção superficial que se dividia em lamelas, presença de epitélio cristaliniano irregular, com áreas de rarefação, usualmente correspondente aos pontos de exfoliação (Figura 2).

\section{DISCUSSÃO}

A exfoliação verdadeira da cápsula é bastante rara, em uma revisão recente Kulkarni e colaboradores, encontraram 35 casos descritos e descreveram mais $\operatorname{cinco}^{(3)}$. O aspecto à biomicroscopia é bastante típico, com a presença de lamelas da cápsula anterior com uma extremidade livre na câmara anterior, curvada sobre ela mesma e aderida na área central, este aspecto pode também ser confirmado por tomografia de coerência óptica ou ultra-sonografia do segmento anterior do olho $^{(1-4)}$. Porém devido à delicadeza destas lamelas, a doença pode facilmente passar despercebida em um exame pouco minucioso ${ }^{(2-4)}$. Um pouco mais freqüente, é o sinal do duplo anel na capsulorrexe, que parece ser um estágio subclínico da esfoliação verdadeira e compartilha com esta o mesmo aspecto anátomo-patológico. A ocorrência deste sinal têm sido relatada em 5 a $40 \%$ das cirurgias de catarata $^{(6-7)}$.

O principal diagnóstico diferencial é com a pseudoexfoliação, embora os aspectos biomicroscópico e anátomopatológico sejam completamente diversos. Outra diferença marcante entre as suas doenças é a associação com o glaucoma, que na exfoliação verdadeira parece ser simples coincidência, como no nosso caso 1 , enquanto na pseudoexfoliação o material acumulado sobre a cápsula anterior também se deposita e acaba por obstruir o trabeculado, levando ao aumento da pressão intra-ocular ${ }^{(2-3)}$.

Algumas teorias foram propostas para explicar a patogênese da exfoliação verdadeira, relacionando a doença aos seus fatores de risco mais conhecidos: exposição ao calor e, mais raramente, inflamação intra-ocular ${ }^{(2,4-5,8-9)}$. A mais aceita é de que o tecido iriano absorveria o calor e o transmitiria para a cápsula anterior. $\mathrm{O}$ efeito térmico poderia resultar em sofrimento do epitélio do cristalino com conseqüente enfraquecimento de sua membrana basal - a cápsula anterior ${ }^{(2,4)}$. Uma outra possibilidade, que não exclui a primeira, é que o calor transmitido à cápsula anterior pela íris, cause proteólise $\operatorname{direta}^{(2,8)}$. Outros possíveis mecanismos envolvidos são anormalidades em proteína capsular e o efeito mecânico da midríase em uma cápsula enfraquecida por reação inflamatória $^{(2,5,9)}$. Apesar destes fatores de risco reconhecidos, alguns pacientes idosos com exfoliação verdadeira não apresentam nenhum deles, como os nossos dois $\operatorname{casos}^{(4)}$.

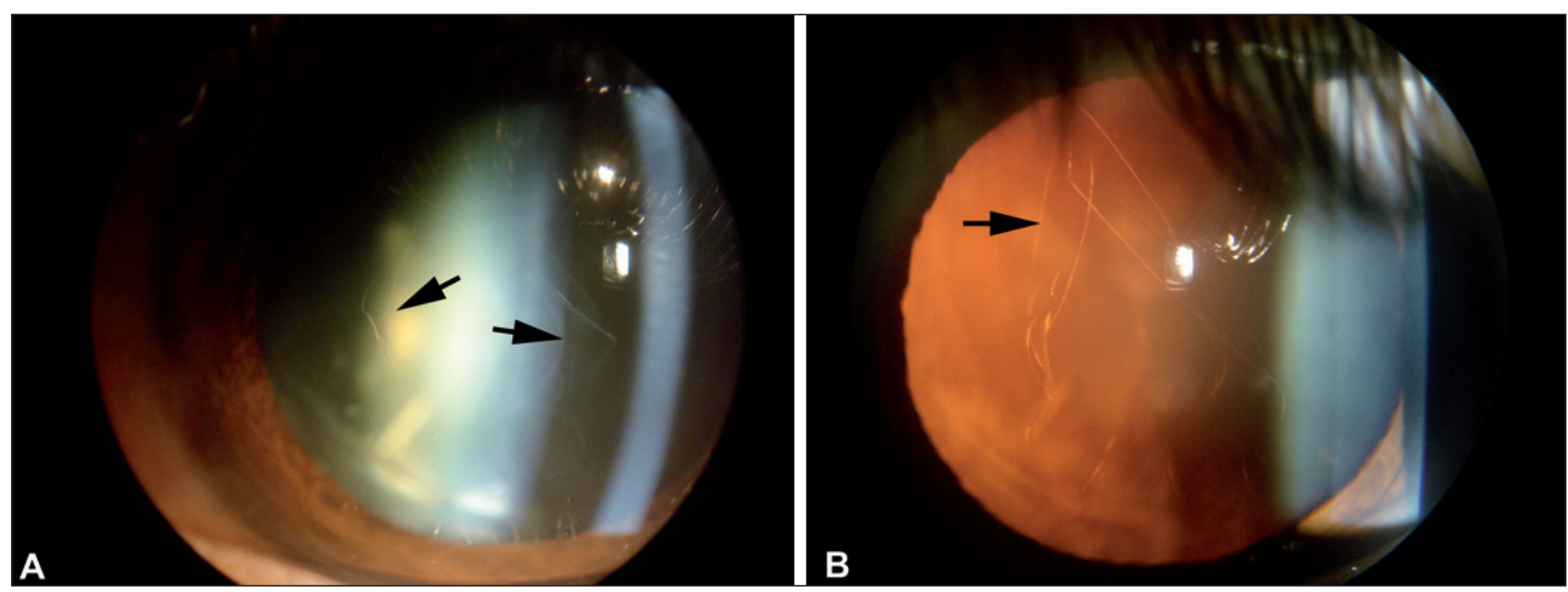

Figura 1 - Caso 1. A) Aspecto biomicroscópico em fenda lateral, lamelas da cápsula anterior (setas) com borda livre na câmara anterior e base aderida à porção central da cápsula. B) Aspecto à retroiluminação (seta) 


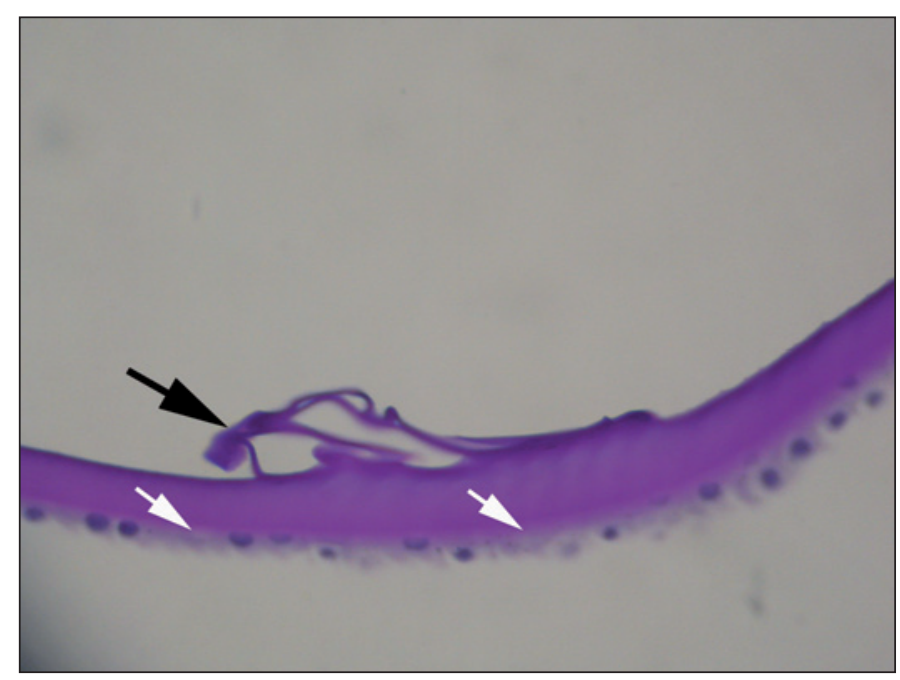

Figura 2 - Caso 2. Aspecto microscópico. Notar cápsula anterior com espessamento central e divisão em múltiplas lamelas (seta negra). Nas áreas de início de exfoliação é possível notar a rarefação do epitélio do cristalino. (PAS 400X).

O aspecto anátomo-patológico é típico, com espessamento da cápsula anterior e delaminação de suas camadas superficiais, presença de epitélio cristaliniano irregularmente distribuído, com células em número e tamanho menores que o habitual $^{(2,4,8-9)}$. Recentemente, Cooke et al. acrescentaram à descrição dos achados anátomo-patológicos, a presença de vesículas próximas aos pontos de exfoliação ${ }^{(2)}$. Este último achado, foi o único que não foi encontrado em nosso caso 2.

Quanto ao prognóstico cirúrgico, os relatos apontam para um bom prognóstico, embora seja aconselhável fazer uma capsulorrexe por fora da área de exfoliação ou, no caso da capsulorrexe em duplo anel, realizar capsulorrexe contínua nos dois planos ${ }^{(2-3,6-7)}$. Apesar destes relatos favoráveis, é importante chamar a atenção do oftalmologista para esta doença rara e que facilmente pode passar despercebida, pois pode resultar em uma capsulorrexe irregular e possíveis complica- ções durante a cirurgia de catarata, fato que pode ter ocorrido na cirurgia do OD do nosso caso 1 e cuja importância tem sido usualmente destacada nos relatos sobre o tema ${ }^{(2-3,6-7)}$.

\section{ABSTRACT}

We report two cases of true capsular exfoliation occurring in elderly patients with no known history of prolonged heat exposure or intraocular inflammation. The biomicroscopic aspects, histopathologic findings and possible surgical implications are discussed.

Keywords: Lens capsule, crystalline/pathology; Lens capsule, crystalline/surgery; Lens disease/pathology; Lens disease/diagnosis; Lens disease/surgery; Case reports [Publication type]

\section{REFERÊNCIAS}

1. Elschnig A. Detachment of the zonular lamellae in glassblowers. Klin Monatsbl Augenheilkd. 1922;69:732-34.

2. Cooke CA, Lum DJ, Wheeldon CE, Teoh H, McGhee CN. Surgical approach, histopathology, and pathogenesis in cataract associated with true lens exfoliation. J Cataract Refract Surg. 2007;33(4):735-8.

3. Kulkarni AR, Al-Ibrahim J, Haider S, Elsherbiny S, Scott R. Phacoemulsification in true exfoliation of the lens capsule: a case series. Eye. 2007;21 (6):835-7.

4. Cashwell LF Jr, Holleman IL, Weaver RG, van Rens GH. Idiopathic true exfoliation of the lens capsule. Ophthalmology. 1989;96(3):348-51.

5. Yamamoto N, Miyagawa A. True exfoliation of the lens capsule following uveitis. Graefes Arch Clin Exp Ophthalmol. 2000;238(12):1009-10.

6. Ataka S, Kohno T, Kurita K, Wada S, Takahashi Y, Shiraki K. Histopathological study of the anterior lens capsule with a double-ring sign. Graefes Arch Clin Exp Ophthalmol. 2004;242(3):245-9.

7. Wollensak G, Wollensak J. Double contour of the lens capsule edges after continuous curvilinear capsulorhexis. Graefes Arch Clin Exp Ophthalmol. 1997;235(4):204-7.

8. Callahan A, Klien BA. Thermal detachment of the anterior lamella of the anterior lens capsule; a clinical and histopathologic study. AMA Arch Ophthalmol. 1958;59(1):73-80.

9. Anderson IL, van Bockxmeer FM. True exfoliation of the lens capsule. A clinicopathological report. Aust N Z J Ophthalmol.1985;13(4):343-7.

\section{Envie seu trabalho pelo site dos ABO}

www.aboonline.com.br 